\title{
A NATUREZA EVOLUTIVA DAS EMOÇÕES BÁSICAS: UMA INVESTIGAÇÃO DO ORGULHO E DA VERGONHA ${ }^{1}$
}

The evolutionary nature of basic emotions: an investigation of pride and shame

La naturaleza evolutiva de las emociones básicas: una investigación del orgullo y la vergüenza

Matheus de Mesquita Silveira ${ }^{2}$ Universidade de Caxias do Sul, Caxias do Sul, RS, Brasil.

\section{Resumo}

O presente artigo tem como objetivo estabelecer o papel que a constituição biológica de mamíferos e as construções culturais têm na expressão de emoções sociais básicas. A relevância social das emoções será investigada a partir da discussão entre o evolucionismo e o construtivismo, com enfoque no papel dos movimentos expressivos na sua comunicação em diferentes espécies de animais e culturas humanas. $O$ estudo relativo às expressões emocionais será realizado mediante a apresentação dos princípios gerais das emoções desenvolvidos por Darwin (2000) em combinação com as análises contemporâneas realizadas pelas ciências naturais sobre o tema. Como estudo de caso, será apresentada a pesquisa desenvolvida por Tracy e Matsumoto (2008), onde é realizada uma comparação das expressões de orgulho e vergonha em humanos com visão normal e cegueira congênita. O argumento é que, caso esses

O presente artigo foi desenvolvido com apoio da FAPERGS/CAPES, a partir do edital 04/2019 - auxílio recém-doutor.

2 Doutor em filosofia pela Universidade do Vale do Rio dos Sinos (UNISINOS). Professor do Programa de Pós-Graduação em Filosofia da Universidade de Caxias do Sul (UCS), Caxias do Sul, Rio Grande do Sul, Brasil. ORCID: https://orcid.org/o0oo-0002-5774-6554. E-mail:mdm.silveira@gmail.com 
princípios sejam homólogos em diferentes espécies ou, ainda, expressos da mesma forma em humanos incapazes de mimetizá-los pelo olhar, então uma explicação evolucionista sobre a relação entre emoções e comportamento tende a ganhar força.

Palavras-chave: Emoções. Expressão. Naturalismo. Evolucionismo. Construtivismo.

\begin{abstract}
The present article aims to establish the biological constitution of mammals and cultural constructions role in basic social emotion expressions. Emotions' social relevance will be grounded on the discussion between evolutionary psychology and social constructivism, focusing on the role of expressions in its communication among different species of animals and human cultures. The study of emotional expressions will be done by presenting the general principles of emotions as it was developed by Darwin (2000), in combination with contemporary analyzes by the natural sciences. As a case study, it will be presented a research developed by Tracy and Matsumoto (2008), comparing expressions of pride and shame in humans with normal vision and congenital blindness. The argument consists that, in case of these principles being homologous in different species or expressed in humans unable to mimic them through observation, then an evolutionary explanation of the relationship between emotions and behavior tends to be strengthen.
\end{abstract}

Keywords: Emotions. Expressions. Naturalism. Evolutionism. Constructivism.

\title{
Resumen
}

Este artículo pretende establecer el papel que la constitución biológica de mamíferos y las construcciones culturales tienen en la expresión de las emociones sociales básicas. La importancia social de las emociones será investigada partiendo de la discusión entre evolucionismo y constructivismo, centrándose en el papel de los movimientos expresivos en la comunicación en las diferentes especies de animales y culturas humanas. El estudio relativo a las expresiones emocionales será realizado mediante la presentación de los principios generales de las emociones desarrollados por Darwin (2000) en combinación con análisis contemporáneos de las ciencias naturales sobre el tema. Como estudio de caso, será presentada la investigación elaborada por Tracy y Matsumoto (2008), donde se hace una comparación de las expresiones de orgullo y vergüenza en los seres humanos con visión normal y ceguera congénita. El argumento es que si estos principios son homólogos en diferentes especies, o, todavia expresos de la misma manera en los seres humanos incapaces de imitar por medio de la mirada, entonces una explicación evolucionista sobre la relación entre las emociones y el comportamiento tiende a ganar fuerza.

Palabras clave: Emociones. Expresión. Naturalismo. Evolucionismo. Constructivismo. 


\section{Introdução}

Emotivismo é como a tradição filosófica demarcou a posição de que as emoções consistem na base dos comportamentos normativos. Os embates acerca desse posicionamento constantemente giram em torno de questões acerca do cognitivismo e do não cognitivismo. Todavia, uma questão centralà adoção de um emotivismo evolucionista não tem o mesmo espaço dentro das discussões contemporâneas em metaética. Considerando a improbabilidade de considerar qualquer emoção como motivadora de comportamentos normativos, o problema converge precisamente na direção de uma investigação sobre a natureza das emoções. A hipótese trabalhada é que expressões de aprovação e censura social estão vinculadas a respostas emocionais. Caso seja verdadeira, então será comprovada também a intuição filosófica de que emoções sociais básicas são motivacionais no que toca comportamentos normativos. Sendo assim, uma expressão emocional consistiria em um juízo acerca do comportamento que engatilhou determinada emoção. Afinal, é plausível considerar que julgamentos sobre o que é vergonhoso ou asqueroso depende da capacidade de sentir vergonha ou nojo.

Em alguma medida, as teorias emotivistas sustentam que as distinções avaliativas presentes em comportamentos normativos são baseadas em processos emocionais. O ponto de divergência está exatamente na natureza das emoções, posto que elas são definidas de formas diferentes por abordagens evolucionistas, culturalistas e compatibilistas. Nesse sentido, um posicionamento emotivista, qualquer que seja, não pode ser impreciso em sua compreensão das emoções. A questão acerca da natureza dos processos emocionais é genuinamente empírica e têm sido foco de estudo tanto da biologia evolutiva, quanto da psicologia cognitiva. Desta forma, é relevante à discussão considerar as descobertas nestas áreas, a fim de identificar quais emoções estão relacionadas a comportamentos normativos. Neste artigo, pretende-se circunscrever a ambição emotivista à explicitação de pressupostos tácitos destas ciências, os quais são considerados essenciais na defesa de um posicionamento evolucionista. Portanto, o caminho para 
avançar na discussão será conectar as perspectivas filosóficas suscitadas pelo emotivismo com os estudos empíricos sobre a fisiologia das emoções.

Há dois escopos teóricos conflitantes sobre a origem das emoções. Perspectivas evolucionistas as colocam como adaptações funcionais, sendo compreendidas dentro do processo de seleção natural. Por sua vez, abordagens construtivistas defendem que as emoções são constituídas por diferentes ethos culturais. Na verdade, ambos os escopos teóricos possuem evidências para sustentar a sua posição. Devido a esse fato, surgiu uma visão compatibilista, na qual algumas emoções são naturais, as quais são consideradas básicas, enquanto outras são mais complexas e construídas culturalmente. A posição sustentada neste artigo é que não se deve adotar um reducionismo biológico acerca das emoções, tampouco se aliar ao argumento de que elas resultam em sua totalidade da cultura humana. Por sua vez, as aproximações compatibilistas entre evolucionismo e construtivismo são ingênuas ao simplesmente dividir as emoções em duas classes distintas. A questão central é que o emotivismo evolucionista pode compreender os processos emocionais como adaptações funcionais dentro de interações pautadas por uma sociabilidade natural. Caso essa perspectiva seja possível, desconstrói-se a dicotomia entre evolucionismo e construtivismo. Afinal, as emoções teriam se desenvolvido a partir de sua função social, porém com base em sistemas biológicos de sociabilidade, enraizando na natureza a sua origem.

Para avançar nesta questão é necessário analisar dois pontos. O primeiro consiste em compreender se existe alguma diferença na fisiologia de mamíferos sociais que permita diferenciar emoções básicas das socialmente desenvolvidas. Caso não seja possível, então os processos emocionais estariam ancorados em estruturas homólogas existentes nestas diferentes espécies. O segundo ponto toca a conceptualização de quais são as emoções básicas. Em uma perspectiva construtivista, pode soar estranho caracterizá-las dessa forma, posto que no momento em que falamos sobre as emoções, elas estariam culturalmente informadas. Ainda que se conceda esse ponto ao construtivismo, disso não decorre que as emoções resultem de construções culturais. Pelo contrário, a questão central está exatamente na defesa de 
que elas não perdem a sua função social se forem compreendidas como resultantes da fisiologia natural tanto de humanos, como de outros animais.

\section{Emoções segundo o construtivismo}

Os críticos do evolucionismo argumentam que as emoções são construídas culturalmente. Embora possua menos adeptos hoje que no passado, é errado supor que essa linha teórica é fraca ou carece de evidências. Da mesma forma que a perspectiva evolucionista, a abordagem construtivista é apoiada por argumentos bastante sólidos. A principal crítica construtivista está na ideia de que o evolucionismo possui uma definição incorreta sobre a natureza das emoções. Em linhas gerais, a perspectiva evolucionista defende que uma emoção consiste na percepção instintiva expressa por alterações corporais padronizadas. A funcionalidade adaptativa das reações emocionais está em preparar o organismo para responder adequadamente à determinada situação.

Averill (1980) rejeita essa possibilidade, defendendo que emoções não são instintivas, involuntárias ou corporificadas, mas apreciações cognitivas embasadas dentro de um roteiro comportamental. Em outras palavras, uma emoção representa uma disposição interna agradável ou desagradável, manifestada por comportamentos de interesse ou preocupação. $O$ roteiro comportamental consiste na instrução sobre o que fazer na presença do objeto de interesse ou preocupação.

[...] as emoções não são apenas reminiscências de nosso passado filogenético, nem podem ser explicadas em termos estritamente fisiológicos. Pelo contrário, são construções sociais, e elas só podem ser plenamente entendidas em um nível social de análise (AVERILL, 1980, p. 309, tradução nossa)³.

3 Do original: [...] emotions are not just remnants of our phylogenetic past, nor can they be explained in strictly physiological terms. Rather, they are social constructions, and they can be fully understood only on a social level of analysis. 
Cada roteiro comportamental possui uma gama diferente de ações, variando das mais simples às mais complexas. As apreciações cognitivas e os roteiros comportamentais inerentes a elas refletem os valores e as convicções de determinado grupo cultural. Nessa abordagem, a emoção está associada ao ato de tomada de decisão relativa à norma dentro da cultura na qual se está inserido. A ação reflete a capacidade de escolha, pois culturas diferentes seguem roteiros comportamentais distintos e, consequentemente, apresentam diferenças na apreciação cognitiva.

Averill (1980) destaca que emoções representam escolhas voluntárias que são apenas tratadas como involuntárias, sendo que a sua presença dispensa qualquer manifestação corporificada. Essa correlação é considerada como ilusória, pois há uma tendência de associar emoções com manifestações corporificadas, bem como a noção de que estados emocionais estão baseados em processos desencadeados pelo sistema nervoso. Contudo, o autor coloca que as emoções são construções da mente e não experiências corporificadas, consistindo em juízos cognitivos de estímulos socialmente relevantes. Sendo assim, seria possível sentir uma emoção sem que ocorresse uma alteração nos batimentos cardíacos. Neste ponto, o erro do evolucionismo apontado pelo construtivismo está na compreensão das emoções enquanto reações instintivas, em vez de apreciações cognitivas.

A estratégia argumentativa para defender essa posição consiste em apresentar emoções que aparentemente não estão associadas a expressões corporificadas facilmente identificáveis. Por exemplo, enquanto o medo e a raiva possuem uma fisiologia expressiva clara, a culpa não apresenta uma manifestação expressiva claramente definida, motivo pela qual é bastante utilizada em exemplos dentro da abordagem construtivista. Averill (1980) ressalta que a culpa pode ser sentida sem que haja qualquer expressão corporal, podendo inclusive durar por um longo período. Por estar associada a padrões complexos de comportamento social, ela também é apontada pelo construtivismo como exemplo de uma apreciação cognitiva que segue um roteiro comportamental, em vez de ser uma mera reação de natureza instintiva. 
Comportamentos de retratação são consequências usuais da culpa, seja através de expressões de arrependimento ou melhora na conduta em situações semelhantes no futuro. Tanto atos deste tipo quanto aqueles pautados por emoções positivas são centrais à vinculação emocional. Frank (1988) traz uma perspectiva evolucionista, onde vinculações desta natureza intensificam a sociabilidade, posto que o prazer associado ao convívio social pode inclinar os membros de pequenos grupos a reprimir prazeres imediatos em detrimento do bem-estar coletivo. $O$ ponto de discordância entre esta perspectiva e 0 construtivismo é que, para o segundo, tais comportamentos são concebidos como indícios de aculturamento e não consistem em adaptações evolutivas.

Em uma linha culturalista, as emoções socialmente relevantes são colocadas como respostas a situações demasiadamente complexas para serem reduzidas a expressões instintivas. Por exemplo, os gatilhos sociais que incitam a vergonha são relativos ao modo como são estabelecidas as normas dentro de determinado grupo. Por sua vez, a mera suspeita do engodo poderá desencadear a desconfiança e ter como consequência ideações paranoides capazes de causar a ruptura de uma vinculação social. Na abordagem construtivista, as interações que engatilham essas emoções são voluntárias e resultam de construções culturais, em vez de expressões instintivas de base biológica. O ponto de discussão consiste em compreender em que medida relações sociais baseadas em emoções são constituídas voluntariamente ou resultam de sistemas adaptativos desenvolvidos pelo processo evolutivo.

A divergência entre o construtivismo e o evolucionismo ocorre inclusive na definição de quais emoções possuem amplitude biológica. Por exemplo, a raiva é uma emoção facilmente identificada em diferentes espécies a partir de expressões corporais homólogas. Perspectivas evolucionistas a conceituam como um elemento motivacional a comportamentos agressivos.

Emoção e motivação são difíceis de separar, pois tendem a vir juntas. As emoções geralmente causam motivações e as motivações geralmente são causadas pelas emoções. A raiva pode causar uma motivação para agredir. A fome pode ser 
causada pela aflição acerca da falta de comida (PRINZ, 2004, p. 195 , tradução nossa) ${ }^{4}$.

Greenspan (2000) credita à raiva maior complexidade cognitiva, defendendo que ela é usada estrategicamente para manifestar indignação ou obter algum benefício social. Solomon (1980) corrobora esta hipótese, ressaltando que a expressão da raiva envolve uma conceptualização complexa do mundo. Esta complexidade estaria na capacidade de compreender uma ação como ofensiva, o que requer, dentro de um contexto social, a existência de um sistema normativo que identifique certo ato como uma ofensa. Esta abordagem coloca a raiva como um roteiro comportamental complexo embasado em uma apreciação cognitiva de caráter normativo.

Mais importante, significa fazer-se ver a situação de uma determinada maneira - não trazendo diretamente um conjunto dos sintomas fisiológicos ou fenomenológicos da raiva. Caso os sintomas afetivos usuais surjam, eles surgem como um resultado da visão das coisas pelo agente (GREENSPAN, 2000 , p. 474, tradução nossa) .

A variação cultural é apontada pelo construtivismo como determinante para explicar o motivo de existirem diferentes gatilhos para uma mesma emoção. Por exemplo, a raiva é tomada pela perspectiva evolucionista como uma emoção básica facilmente identificada pela expressão corporal. No entanto, Briggs (1970) ressalta que expressões de raiva são raramente vistas entre membros da mesma tribo dentro da cultura Inuit, ainda que todos apresentem agressividade em ações de caça e defesa de território.

\footnotetext{
4 Do original: Emotion and motivation are difficult to tease apart, because they tend to come together. Emotions often cause motivations, and motivations are often caused by emotions. Anger can cause a motivation to aggress. Hunger can be caused by distress about a lack of food.

5 Do original: Most important, it means making oneself see the situation in a certain way-not directly bringing on a set of physiological or phenomenological symptoms of anger. If the usual affective symptoms emerge, they emerge as a result of the agent's view of things.
} 
O problema é que o motivo apresentado é compatível com uma explicação evolucionista, ou seja, que respostas agressivas seriam disfuncionais em pequenos grupos vivendo sob condições adversas ${ }^{6}$.

Descrições de outras reações emocionais presentes no oriente, mas que não possuem uma analogia clara no ocidente, também são utilizadas para sustentar a hipótese das emoções possuírem um fundamento cultural. Por sua vez, Doi (1973) identifica o termo japonês amae como a sensação de indulgente dependência em relações parentais. No ocidente, essa relação é encontrada em crianças, mas não se manifesta da mesma forma em adultos. Markus e Kitayama (1991) descrevem a palavra oime como um endividamento emocional, enquanto o termo fureai se refere a sensação de vinculação afetiva. A orientação coletivista da cultura japonesa é apontada pelos autores como responsável pela riqueza do vocabulário no que toca a descrição de relações de interdependência. Uma abordagem construtivista traz isso como evidência de que os japoneses ou malaios sentem emoções estranhas aos que nasceram no seio de culturas ocidentais. A crítica evolucionista é que, da inexistência ou precisão de uma definição linguística relativa a uma emoção, não decorre a incapacidade de senti-la.

A especificidade linguística dos termos mencionados anteriormente é apontada como evidência da base cultural das emoções. Neste sentido, elas são consideradas como apreciações cognitivas e não como universais biológicos. Entretanto, ainda que as emoções sejam engatilhadas por contextos variados e que a sua intensidade seja regulada por fatores externos, ou que o vocabulário de culturas diferentes sejam mais ou menos precisos em sua descrição, disso não decorre que a capacidade de as sentir não seja universal. Uma hipótese compatível com uma perspectiva evolucionista é que a cultura, ou outros fatores externos, podem regular o grau de

\footnotetext{
6 Mech (1999) relata em sua pesquisa um comportamento homólogo em lobos do ártico (Canis lupus arctos), apontando que demonstrações de agressividade e disputas hierárquicas são raras entre lobos selvagens. Segundo o autor, o gasto energético despendido em confrontos internos enfraqueceria a alcateia, tornando a defesa de território e a proteção dos filhotes mais difícil. Contudo, eles têm a mesma agressividade ao caçar da apresentada por outros predadores.
} 
intensidade ou a forma como uma emoção será sentida. Contudo, isso somente é possível por existir uma base biológica apta a receber estas influências. Esse ponto é essencial para defender uma posição evolucionista com relação às emoções e, na intenção de desenvolvê-lo, a próxima sessão apresentará a perspectiva evolucionista acerca das emoções.

\section{Emoções segundo o evolucionismo}

De uma forma geral, o evolucionismo compreende as emoções como adaptações resultantes de seleção natural. Elas são reações psicobiológicas que foram selecionadas a partir de sua funcionalidade no decorrer do processo evolutivo. O ponto de discordância está na definição de quais emoções podem ser consideradas como básicas. Prinz (2004) distingue entre modestas e imodestas as teorias que as restringem em menor ou maior grau?.

Em seu estudo sobre o reconhecimento pancultural de expressões emocionais, Ekman et al. (1969) identificaram a alegria, a tristeza, o medo, a surpresa, a raiva e o nojo como emoções básicas. Por exemplo, foi observado que os mesmos gatilhos incitam essas emoções tanto nos Fore $^{8}$, quanto nas culturas ocidentais. Foi constatado que os membros dessa tribo relaciona o nojo com comidas apodrecendo, a raiva com insultos pessoais e a tristeza com a morte de um membro da tribo. $\mathrm{O}$ ponto é que esse fato reforça a hipótese de que essas emoções possuem uma natureza psicobiológica, sendo denominadas como básicas por não conterem outros elementos como parte de sua composição.

Há maior plausibilidade em considerar que emoções expressadas por uma ou mais espécies sejam parte de sua estrutura psicobiológica, do que

Dentre os autores classificados como imodestos estão Frank (1988), Pinker (1997) e Ekman (1999), ainda que o trabalho inicial de Ekman (1969) seja considerado como uma teoria modesta sobre as emoções básicas.

8 Os Fore vivem no distrito de Okapa, na província oriental da Nova Guiné. Há aproximadamente 20000 membros, espalhados pela Cordilheira Wanevinti entre as regiões Norte e Sul. Sua linguagem apresenta três dialetos distintos e a principal forma de sobrevivência consiste na agricultura de coivara. 
resultantes de uma aprendizagem uniforme e universal. Consideradas como complexas nos estudos iniciais de Ekman (1969), o orgulho e a vergonha passaram a integrar o grupo das emoções básicas nos seus trabalhos posteriores. De fato, Ekman (1999) acrescenta à lista inicial de emoções básicas a diversão, o desprezo, o contentamento, o constrangimento, o entusiasmo, a culpa, o alívio, o prazer sensorial, o orgulho e a vergonha.

\begin{abstract}
[...] o adjetivo "básico" é para indicar, em vez disso, que as emoções evoluíram para o seu valor adaptativo ao lidar com tarefas fundamentais da vida. Fatores inatos desempenham um papel em contabilizar as características que elas compartilham, não no aprendizado constante e variável da espécie (EKMAN, 1999, p. 46, tradução nossa) 9 .
\end{abstract}

Uma forma comum de investigar a hipótese evolucionista é estabelecer o quão universais são estas emoções. Ainda que possa reforçar essa perspectiva, a crítica consiste em que a universalidade não implica necessariamente uma base psicobiológica às emoções. Por exemplo, da crença universal de que o sol é quente não decorre uma fundamentação evolucionista para a mesma. Afinal, o sol é quente em qualquer parte do planeta e habilidades gerais de aprendizagem combinadas com um elemento ambiental em comum podem ser suficientes para explicar a sua universalidade. Contudo, o ponto da perspectiva evolucionista é que, ainda que essa crença possa resultar de um aprendizado empírico, os sistemas que permitem sua formação são psicobiológicos e compartilhados por todos os membros de determinadas espécies.

No que toca o universalismo das emoções básicas, uma base adequada de comparação pode ser feita com a percepção das cores e da música. A despeito das variações ambientais, Prinz (2004) salienta que todos os três elementos estão presentes em diferentes culturas. Ainda que a am-

\footnotetext{
9 Do original: [...] the adjective "basic" is to indicate instead the view that emotions evolved for their adaptive value in dealing with fundamental life tasks. Innate factors play a role in accounting for the characteristics they share, not species-constant or species-variable learning.
} 
plitude do espectro das cores não encontre uma analogia óbvia no mundo natural, o seu espaçamento é realizado de modo semelhante tanto no ártico, quanto no deserto ou na floresta ${ }^{10}$. Com relação à música, é possível encontrar semelhanças em sua apreciação entre primatas. Wright (2000) observou que macacos (Macaca mulatta) preferem composições tonais organizadas em oitavas. Esses animais têm a capacidade de reconhecer semelhanças em melodias idênticas tocadas em oitavas diferentes. Da mesma forma, culturas isoladas umas das outras têm sistemas musicais semelhantes, com as composições tonais prevalecendo sobre as atonais" ${ }^{11}$.

$\mathrm{O}$ aspecto do aprendizado é relevante à discussão. Em uma perspectiva evolucionista, as crenças são formadas devido a sistemas psicobiológicos aptos a gerá-las. Dito de outra forma, estímulos externos são apreendidos por uma estrutura interna de modo a estabelecer conexões causais capazes de direcionar comportamentos. Desta forma, gatilhos são estímulos externos e as emoções estruturas internas, fazendo com que a expressão de uma emoção tenha uma natureza semelhante a um espirro, ou seja, em ambos os casos não existem inferências causais. Espirrar é uma resposta instintiva para uma irritação nas vias nasais engatilhada por um agente externo. Mesmo sendo possível estimular intencionalmente essa reação, ela está ordinariamente aquém do controle voluntário e não necessita de qualquer aprendizado para ser executada.

Prinz (2004) defende que emoções não constituem crenças, não sendo adquiridas por inferências causais a partir da experiência. Desta forma, elas possuem uma natureza instintiva e involuntária e não derivam de um aprendizado intencional. Assim como espirros, as emoções estão intrinsecamente ligadas a reações corporais. Damasio (1999) sustenta uma posição corporificada sobre a questão, sustentando que sistemas

\footnotetext{
10 Um maior aprofundamento a percepção das cores em diferentes culturas poderá ser encontrado em Davidoff et al. (1999) e Roberson e Davidoff (2005).

$"$ Uma possível explicação para o fato de culturas isoladas terem o mesmo sistema musical pode estar relacionada ao fato de que a separação tonal respeita as leis da física. Em outras palavras, a próxima oitava de uma nota tem exatamente o dobro de vibrações, constituindo a sexta em uma razão 2/1; a quinta em uma razão de 2/3; a quarta em uma razão de $3 / 4$ e assim sucessivamente.
} 
cerebrais vinculados a respostas emocionais estão associados à percepção e à produção de respostas corporais padronizadas. Esta posição ecoa a análise de Maclean (1993), em particular na defesa de que esses sistemas cerebrais são filogeneticamente antigos, com répteis possuindo estruturas homólogas com as relacionadas às emoções humanas.

Emoções são coleções complicadas de respostas químicas e neuronais, formando um padrão; todas as emoções têm algum tipo de papel regulador a desempenhar, levando de uma forma ou de outra para a criação de condições vantajosas para o organismo exibindo o fenômeno; emoções são sobre a vida de um organismo, o seu corpo para ser mais preciso, e seu papel é ajudar o organismo na manutenção da vida (DAMASIO, 1999, p. 51, tradução nossa) ${ }^{12}$.

A perspectiva corporificada é central na posição apresentada por James (1922) e Lange (1922), para quem a emoção é a expressão de alterações padronizadas no corpo. De fato, a teoria de James-Lange coloca as emoções como enraizadas em sistemas cerebrais ancestrais. Dito de outra forma, elas são expressões corporificadas cuja base psicobiológica é compartilhada por inúmeras espécies. Sendo assim, evidências empíricas que atestem uma relação entre expressões corporificadas e emoções básicas socialmente relevantes não apenas contribuirão para a defesa de uma perspectiva evolucionista à questão, como também reforçarão o argumento naturalista sobre o papel das emoções no comportamento normativo.

\footnotetext{
12 Do original: Emotions are complicated collections of chemical and neural responses, forming a pattern; all emotions have some kind of regulatory role to play, leading in one way or another to the creation of circumstances advantageous to the organism exhibiting the phenomenon; emotions are about the life of an organism, its body to be precise, and their role is to assist the organism in maintaining life.
} 


\subsection{Emoções como adaptação evolutiva}

Na sessão anterior foram apresentados argumentos em defesa da hipótese de que as emoções possuem uma base psicobiológica. Todavia, nenhum deles avança satisfatoriamente sobre a possibilidade de serem adaptações evolutivas. O medo é um bom exemplo para abordar esse ponto. Plutchik (1980) sustenta que a sua função é preparar o corpo para enfrentar um perigo iminente através de expressões e reações corporais padronizadas, as quais auxiliarão no combate ou na fuga. A sobrevivência de qualquer animal está associada à sua capacidade de enfrentar ou evitar o perigo e, neste sentido, qualquer sistema psicobiológico que agregue eficiência a esses comportamentos foi preservado no processo de seleção natural.

É necessário a uma perspectiva evolucionista apresentar a funcionalidade adaptativa das emoções. Afinal, para elas terem se desenvolvido pelo processo de seleção natural, é preciso que possuam valor adaptativo relativo à sobrevivência de determinadas espécies. Prinz (2004) identifica no medo, na raiva e no nojo os melhores candidatos para representar esta relação, posto que são usualmente sentidos em contextos onde há risco de vida. No entanto, uma explicação desta natureza também pode ser aplicada às emoções socialmente relevantes, tais como o orgulho e a vergonha.

É um ponto pacífico nas discussões de viés evolucionista que estas emoções são essenciais não apenas em relações rígidas de dominação e submissão, mas principalmente em estruturas sociais flexíveis, atuando na inibição do engodo e da traição. Embora a trapaça que vise alto ganho a um baixo risco esteja presente no comportamento de inúmeras espécies sociais, ela acarreta grande desvantagem a longo prazo, principalmente pelo ônus social que a descoberta do engodo causa. Ser pego cometendo atos que tragam benefício próprio em detrimento do bem-estar coletivo reduz a harmonia social, prejudicando a reciprocidade entre os membros de pequenos grupos. 
posição vulnerável, porque os trapaceiros serão selecionados para tirar proveito das emoções positivas do altruísta. Isso, por sua vez, engatilha uma pressão seletiva para um mecanismo de proteção (TRIVERS, 1971, p. 49, tradução nossa) ${ }^{13}$.

O mecanismo de proteção identificado por Trivers (1971) é a agressividade normativa e a indignação, ambas derivadas da emoção básica da raiva. Há três pontos vantajosos neste comportamento. O primeiro é neutralizar a tendência altruísta quando não houver reciprocidade, de modo a não manter este comportamento caso não haja recompensa emocional. O segundo consiste em educar os membros do grupo que apresentam comportamento egoísta, assustando-os com um dano imediato ou com o medo futuro de não receber mais ajuda. Por fim, o terceiro e mais extremo, envolve atacar contra os membros egoístas, causando ferimento, exílio ou morte.

A culpa e a vergonha também são emoções básicas de alto valor adaptativo na manutenção de relações sociais, uma vez que estão associadas ao comportamento de importar-se com os danos que as próprias ações causam em terceiros. A própria expressão dessas emoções estimula a inibição da agressividade, pois manifesta uma autopunição e engatilha atos associados ao perdão. Um padrão de comportamento egoísta é prejudicial a longo prazo, visto que reduz as perspectivas de futuras trocas de recursos. Em casos onde o engodo é descoberto, culpa e vergonha são funcionais na manutenção do vínculo social ao sinalizar a autopunição e a consequente improbabilidade da repetição do ato. Em suma, emoções básicas são mecanismos funcionais à promoção do comportamento normativo ao maximizar a reciprocidade em pequenos grupos.

13 Do original: Once strong positive emotions have evolved to motivate altruistic behavior, the altruist is in a vulnerable position because cheaters will be selected to take advantage of the altruist's positive emotions. This in turn sets up a selection pressure for a protective mechanism. 
Caso trapacearmos e sermos pegos, podemos reduzir as perspectivas para futuras trocas recíprocas de recursos. Caso tenhamos a capacidade para a culpa, outros serão mais propensos a cooperar conosco, porque eles saberão que é improvável que os trapaceemos. Caso sejamos pegos trapaceando e apresentarmos sinais de culpa, outros podem nos perdoar e cooperar conosco no futuro. Culpa, portanto, pode ser considerada como um mecanismo que promove o tipo de comportamento que maximiza as perspectivas de trocas recíprocas (PRINZ, 2004, p. 5, tradução nossa) ${ }^{14}$.

Frank (1988) ressalta a importância das emoções na vinculação de longo prazo. Em uma perspectiva evolucionista, estabelecer vínculos desta natureza é vantajoso em espécies que necessitam de alto investimento parental na criação da prole. Benshoof e Thornhill (1979) elencam vários fatores que estabelecem comportamentos pró-sociais como evolutivamente vantajosos. Como exemplo é possível mencionar o auxílio recíproco na obtenção de alimentos e na proteção mútua. Entretanto, cabe ressaltar que ganhos imediatos apresentam respostas emocionais mais intensas, motivo pelo qual são mais tentadores que recompensas de longo prazo. O risco desta tentação é negligenciar o investimento em vínculos de longo prazo. Ainda assim, Mech (1999) salienta que são emoções as responsáveis por estimular lobos (Canis lupus) a viver em grupo. Neste caso, o comportamento social se configura em uma vantagem evolutiva ao ser considerada a fragilidade dos filhotes no nascimento e o trabalho necessário para que sobrevivam aos primeiros meses de vida.

O conflito entre recompensas de curto e longo prazo é suscetível à disponibilidade de recursos externos, como quantidade de alimento e parcei-

\footnotetext{
14 Do original: If we cheat and get caught, we may reduce prospects for future reciprocal exchanges of resources. If we have the capacity for guilt, others will be more likely to cooperate with us, because they will know that we are unlikely to cheat. If we are caught cheating, and show signs of guilt, others may forgive us and cooperate with us in the future. Guilt, therefore, can be regarded as a mechanism that promotes the kind of behavior that maximizes prospects of reciprocal exchange.
} 
ros em potencial. Por exemplo, em espécies com formação de pares, tanto a apreensão da infidelidade alheia, quanto o reconhecimento da própria, afetarão diretamente a capacidade de estabelecer vínculos desta natureza. Emoções básicas como culpa e vergonha estão associadas à autopunição de longo prazo, surgindo na medida em que a satisfação do prazer imediato desaparece. Dito de outra forma, são mecanismos evolutivos que inibem a busca por prazeres intensos e fugazes, exatamente por terem uma característica mais duradoura e permanente, inibindo comportamentos que engatilhariam repreensão e um possível ostracismo social. Portanto, ações pró-sociais não estão baseadas exclusivamente em altruísmo, mas na inclinação de evitar a autopunição emocional advinda de atitudes antissociais.

[...] a infidelidade emocional e sexual está claramente correlacionada, embora de forma imperfeita, e uma porcentagem considerável de homens [...] relatou maior aflição à infidelidade emocional da parceira. Infidelidade emocional pode sinalizar infidelidade sexual e vice-versa e, portanto, ambos os sexos devem ficar angustiados em ambas as formas (BUSS, 1992, p. 255, tradução nossa) ${ }^{15}$.

Em suma, emoções básicas são necessárias para o estabelecimento de vinculação de longo prazo. A alegria e o contentamento resultantes do convívio social, assim como a raiva direcionada aos que quebram as normas, a culpa e a vergonha duradouras que permanecem após o prazer fugaz advindo do engodo, ou o orgulho sentido por ser benquisto pelos seus iguais, tornam animais sociais naturalmente propensos a desenvolverem comportamentos coletivos. Ainda que esta vinculação não se estenda necessariamente por toda a vida, emoções consistem no impulso que motiva muitos animais sociais a

15 Do original: [...] emotional and sexual infidelity are clearly correlated, albeit imperfectly, and a sizable percentage of men [...] reported greater distress to a partner's emotional infidelity. Emotional infidelity may signal sexual infidelity and vice versa, and hence both sexes should become distressed at both forms. 
permanecerem juntos durante os anos em que a prole requer maiores cuidados. Desta forma, emoções básicas são funcionais e adaptativas, o que explica o motivo de serem selecionadas no processo evolutivo e, consequentemente, constituírem em sistemas psicobiológicos inerentes a determinados animais.

\section{Emoções segundo teorias compatibilistas}

Nas sessões anteriores foi apresentado como a abordagem construtivista e a perspectiva evolucionista seguem caminhos opostos para explicar as emoções. Ambas as teorias possuem refinamento teórico e alegam possuir evidências empíricas para sustentar as suas hipóteses. Esta divergência é central em qualquer investigação sobre o tema, o que acarretou tentativas de compatibilizar as duas visões. Em linhas gerais, essa proposta coloca que tanto o construtivismo quanto o evolucionismo estão corretos, mas se aplicam a grupos diferentes de emoções. As de base psicobiológica seriam as evolutivas, enquanto as complexas resultariam da cultura.

Griffiths (1997) defende uma posição compatibilista, definindo que as emoções básicas não são naturais, mas consistem em programas afetivos. As emoções são tomadas como modulares e dotadas de padrões automáticos de resposta semelhantes aos encontrados em espécies não humanas e, apenas nesse sentido, poderiam ser consideradas como produto da seleção natural. Nesta visão, as emoções básicas não decorrem de transmissão filogenética, mas carregam uma demarcada influência cultural, como no caso da expressão amae descrita anteriormente.

Oatley e Johnson-Laird (1987) apresentam uma posição semelhante, salientando que emoções básicas são expressas por vias distintas dependendo da capacidade de processamento de informação de cada espécie. Dito de outra forma, enquanto algumas apresentam respostas instintivas, outras necessitam de maior complexidade cognitiva. A diferença entre emoções básicas e complexas estaria na sua estrutura e apenas as últimas estariam associadas com comportamentos normativos. Nesta visão, 
a capacidade de representação desenvolvida a partir de uma cognição complexa é o que torna as emoções suscetíveis ao aculturamento.

Para que uma emoção ocorra, o sistema cognitivo precisa estar em um módulo de emoção, ou oscilando entre dois. A intensidade de uma emoção corresponde à quantidade de sistema entrelaçado num módulo particular e ao consequente grau de bloqueio deste módulo (OATLEY; JOHNSON-LAIRD, 1987, p. 34, tradução nossa) ${ }^{16}$.

O objetivo desta sessão não é oferecer uma descrição detalhada das teorias compatibilistas, mas situar os pontos centrais da discussão acerca da natureza das emoções. Considerando os bons argumentos sobre a influência tanto dos sistemas psicobiológicos, quanto da cultura sobre essa questão, é plausível colocar uma posição compatibilista como uma resposta adequada. No entanto, há três argumentos para criticar o compatibilismo. O primeiro é que tanto emoções básicas, quanto complexas possuem estruturas homólogas. Ainda que o grau de intensidade possa variar, ambas apresentam respostas corporais associadas a movimentos expressivos, assim como possuem força motivacional e valência capaz de afetar a atenção e a memória. Uma divisão das emoções entre natureza e cultura através de subclasses distintas precisa dar conta de explicar esses fenômenos em sua teoria.

Mesmo que as similaridades entre emoções básicas e complexas possam vir a ser explicadas, ainda permanece a dependência de uma cognição complexa como necessária às emoções. A segunda crítica é que elas podem surgir tanto de sistemas instintivos primitivos quanto do pensamento reflexivo. Por exemplo, a raiva surgir como resposta a uma ameaça iminente ou por um raciocínio sobre as consequências de um comportamento. Por sua vez, o medo advém tanto da perda súbita de suporte quanto de um barulho na

16 Do original: For an emotion to occur, the cognitive system needs to be in one emotion mode or oscillating between two. The intensity of an emotion corresponds to the amount of the system entrained in a particular mode and to the consequent degree of locking into that mode. 
janela ou do resultado de uma eleição para presidente. Prinz (2004) recupera a posição de Darwin (2000), atestando que em todos esses casos as reações corporais expressivas são provocadas pelos mesmos sistemas psicobiológicos. Uma vez que estas emoções emergem da mesma forma, não faz sentido classificá-las pelo grau de complexidade cognitiva que as engatilhou.

Crianças sorriem quando estimuladas, ratos paralisam quando ameaçados e gatos eriçam o pelo quando um predador se aproxima. Essas expressões provavelmente operam sob o controle de estruturas cerebrais que são homólogas as estruturas encontradas em humanos adultos. Se circuitos e expressões emocionais como a nossa são encontrados em organismos que operam fora da nossa cultura, então é estranho atribuir emoções à cultura. Claramente, as emoções têm uma base biológica (PRINZ, 2004, p. 114, tradução nossa) ${ }^{17}$.

Categorizar as emoções a partir do vocabulário usado para descrevê-las e, a partir disso, conceituá-las em básicas e complexas também é problemático. A terceira crítica coloca que definir uma emoção a partir da linguagem reflete mais a importância que cada cultura dá para ela do que a sua natureza. Segundo Prinz (2004), investigar a classificação linguística e cultural das emoções é um exercício interessante, mas que não auxilia na compreensão das bases dos processos emocionais. De modo a não negligenciar totalmente esta metodologia, o que pode ser feito é buscar traços em comuns nas definições de culturas diferentes sobre emoções específicas, para então analisar os processos envolvidos naquilo que lhes é universal. Entretanto, na sessão seguinte delinearei uma forma mais simples e empiricamente válida de fazer a mesma coisa.

\footnotetext{
17 Do original: Infants smile when stimulated, rats freeze when threatened, and cats bristle their hairs when a predator approaches. These expressions probably operate under the control of brain structures that are homologous to structures found in adult humans. If emotional circuits and expressions like ours are found in organisms that operate outside our cultures, then it is odd to attribute emotions to culture. Clearly emotions have a biological basis.
} 
Em suma, caso as emoções sejam separadas em básicas e resultantes do processo evolutivo, ou complexas e culturalmente construídas, então é preciso um critério claro de distinção que dê conta de explicar as similaridades de ambos os processos. Soma-se a isto que tanto a abordagem construtivista, quanto a perspectiva evolucionista usam as mesmas emoções como exemplo. Uma posição compatibilista é relevante se existir uma clara indicação de quais emoções são tomadas como objeto de estudo por uma ou outra linha teórica. No momento em que esta demarcação é imprecisa, simplesmente não faz sentido adotar um compatibilismo nos moldes como foi apresentado nesta sessão.

Creditar às emoções um papel central nas relações sociais não significa que se esteja concedendo espaço aos argumentos construtivistas. A questão é explicar a característica de regulação social inerente às emoções a partir de uma perspectiva evolucionista e, neste sentido, o estudo fisiológico dos movimentos expressivos é de grande relevância. É um ponto relativamente pacífico que um efeito possui a natureza da sua causa. Portanto, caso a expressão emocional tenha uma base biológica e exerça influência na vida em grupo, então a emoção que está sendo expressa terá o mesmo fundamento.

\section{Emoções e movimentos expressivos}

As bases dos estudos em fisiologia das expressões emocionais foram sedimentadas por Bell (1824), cuja principal contribuição foi descobrir a relação entre movimentos expressivos e respiratórios. Duchenne (1876) avançou sobre a questão, ao correlacionar emoções com contrações musculares e sulcos produzidos na pele. A partir desse estudo foi possível identificar quais músculos respondem a ações voluntárias ou involuntárias, possibilitando às ciências naturais mensurar quais expressões são passíveis de controle intencional. Todavia, foi apenas com Darwin (2000) que a relação entre emoções e movimentos expressivos ganhou destaque, em particular no seu valor adaptativo com relação a comportamentos pró-sociais. 
Spencer (1855) identificou que emoções negativas são usualmente expressas pela tensão muscular generalizada. Por exemplo, a expressão do medo tem como características centrais vocalizações intensas e aumento da frequência cardíaca, levando ao aumento da temperatura corporal, eriçamento dos pelos ou enrubescimento da pele. A adrenalina e o estresse apresentam o mesmo tipo de tensionamento e estão associados a expressões como rosnados, protusão de garras e dilatação das pupilas e narinas. A explicação oferecida é que a expressão corporificada de emoções ocorre a partir de descargas do sistema nervoso, a qual se manifesta primeiramente pelas vias habituais e, posteriormente, por expressões secundárias.

A diferença entre Darwin (2000) e os seus antecessores é a perspectiva de existirem estruturas homólogas entre diferentes espécies. Por exemplo, os humanos possuem os mesmos músculos faciais que os macacos antropoides $^{18}$. De fato, a capacidade de expressão emocional pode ser observada em diferentes espécies. Para Darwin (2000, p. 20), “[...] o homem não consegue exprimir com sinais externos amor e humildade tão claramente quanto um cachorro, quando, com orelhas caídas, boca aberta, corpo torcido e cauda abanando, encontra o amado dono". Uma crítica a essa posição é que os músculos envolvidos nos movimentos expressivos não se desenvolveram com essa função específica, pois há diferenças no modo como diferentes espécies expressam emoções. No entanto, a possibilidade dos músculos e, em particular os faciais, possuírem uma função distinta da expressão emocional não os impede de também servirem a esse propósito. O ponto em questão é que tanto o abanar da cauda de um cachorro (Canis lupus familiaris), quanto os olhos umedecidos de quem o encontra são adaptações evolutivas funcionais à vida em pequenos grupos.

18 Os macacos antropoides são uma subdivisão dos primatas, compreendidos como simióides. Eles são separados entre platirríneos, que possuem tabique nasal largo e cauda preênsil. Os catarríneos, dotados de tabique nasal estreito e cauda não preênsil, sendo por vezes reduzida. Além dos pongídeos, sem cauda e capazes de andar em posição ereta ou se apoiar nas extremidades dos membros anteriores. 


\subsection{Princípios dos movimentos expressivos}

Uma vez que movimentos complexos executados automaticamente são aprendidos pelo hábito, é plausível considerar a sua influência também nas expressões emocionais. Darwin (2000) denomina como princípio dos hábitos associados úteis àqueles cuja função é satisfazer ou aliviar uma sensação ou desejo. O ponto é que determinadas expressões se tornam habituais por serem repetidas com grande frequência, pois são realizadas sempre que uma emoção específica é sentida. De fato, a frequência de excitação direcionada às fibras nervosas está relacionada a sua capacidade de condução relativa aos nervos motores. Sendo assim, determinados movimentos expressivos ocorrem a partir de estímulos nas células nervosas que são habitualmente utilizadas na expressão de certas emoções.

Algumas ações complexas têm utilidade direta ou indireta em certos estados de espírito para aliviar ou gratificar sensações, desejos etc., e toda vez que o mesmo estado de espírito é induzido, mesmo que pouco intenso, há uma tendência, pela força do hábito e associação, de os mesmos movimentos se repetirem, ainda que não tenham a menor utilidade (DARWIN, 2000, p. 36).

A intensidade emocional exerce influência direta na capacidade de coordenação motora. Segundo Darwin (2000), isso ocorre porque o princípio ativo dominante do hábito está diretamente associado ao sistema nervoso. Por exemplo, sensações de segurança e bem-estar acarretam a dilatação das pupilas durante uma troca de olhares. A ocorrência contínua desse comportamento faz com que tais órgãos sejam ativados por emoções específicas a partir da associação. Por exemplo, o hábito é o princípio que explica a relação entre coçar a cabeça ou esfregar os olhos diante da sensação de perplexidade. Isso ocorre, porque estes dois movimentos trazem alívio a um corpo tomado pelo desconforto. 
Darwin (2000) coloca que podem ser encontrados comportamentos instintivos com diferentes graus de determinação genética. Por um lado, têm-se a mariposa-beija-flor (Macroglossa), que pode ser observada firmemente inserida nos pequenos orifícios de uma flor assim que abandona o casulo. Desempenhar essa tarefa com tamanha precisão não requer qualquer tipo de aprendizagem. Por outro lado, lobos associam o comportamento de caça a partir de interações lúdicas realizadas desde os primeiros meses de vida. A relação entre os estímulos ambientais e as respostas comportamentais moldam as interações sociais destes animais. Dito de outra forma, elas são instintivas, mas não necessariamente inatas.

Emoções estão vinculadas entre si do mesmo modo que comportamentos. O hábito molda o comportamento normativo ao conectar emoções específicas aos gatilhos ambientais, tornando a associação uma característica central na intensidade com a qual as emoções básicas são expressas. Portanto, uma expressão emocional pode ser o gatilho que fará com que os demais membros do grupo sintam uma emoção associada à que foi expressa. Neste sentido, a associação estabelecida pelo hábito é uma característica útil baseada em um sistema psicobiológico instintivo de aprendizagem que inclina animais sociais a estabelecerem relações de grupo funcionais a partir de um sincretismo emocional.

Expressões emocionais baseadas no princípio dos hábitos associados úteis foram adquiridas fenotipicamente no processo evolutivo. Como resultado, estes movimentos expressivos se tornaram adaptações em determinadas espécies. Desta forma, ainda que alguns movimentos expressivos possuam outra função original que expressar emoções, eles adquiriram esta funcionalidade ao longo da história natural das espécies nas quais estão presentes. Darwin (2000) denomina o segundo princípio como antítese, diferenciando-se na medida em que uma emoção contrária a expressa pelo princípio anterior se manifestará mediante um movimento oposto, ainda que esse não tenha uma utilidade. No caso de humanos, estes movimentos expressivos são muitas vezes confundidos com comportamentos aculturados, motivo pelo qual serão utilizadas outras espécies como exemplo. 
Conforme Mech (2007), o principal modo de comunicação dentro da alcateia é visual e a morfologia de todo o corpo do lobo está envolvida neste tipo de comunicação. Expressões posturais são utilizadas para comunicar a posição social do lobo dentro da alcateia, adquirindo graus de variação com relação a contextos sociais específicos. Intenções hostis são demarcadas pelo caminhar tenso e a contração dos músculos de modo a conferir a explosão muscular necessária à caça ou ao combate. A cauda rígida e erguida, a cabeça levemente inclinada para frente, o olhar fixo com as orelhas levemente voltadas para trás e os caninos expostos também expressam hostilidade. Esses movimentos são expressivos, mas a sua utilidade primária é preparar o corpo do lobo para o esforço necessário para vencer um enfrentamento, seja na caça ou defesa do território.

O comportamento de lobos ao interagirem amistosamente com os demais membros da alcateia é exatamente oposto a esse. O caminhar relaxado está presente em todos os integrantes, com as posições hierárquicas se diferenciando por sutis diferenças nos movimentos do rabo e das orelhas, cuja posição alonga as pálpebras e deixa os olhos mais abertos, expondo a pupila. Esses movimentos expressivos possuem valor adaptativo ao inibir comportamentos agressivos e evitar conflitos internos com lobos da mesma alcateia. Contudo, a sua utilidade é unicamente expressar uma emoção, sem preparar o corpo para qualquer outro tipo de interação. O princípio da antítese explica essas características, uma vez que comportamentos pró-sociais são manifestados por movimentos expressivos exatamente opostos aos presentes em posturas combativas.

No caso tanto do cachorro quanto do gato, temos todos os motivos para acreditar que seus gestos de hostilidade e afeição são inatos ou herdados, pois eles são praticamente idênticos nas diferentes raças da espécie, e em todos os indivíduos da mesma raça, jovens ou velhos (DARWIN, 2000, p. 62). 
Schenkel (1947) relata que lobos exibem uma postura autoinflada tanto em confrontos dentro da alcateia, quanto em situações de perigo externo, aparentando uma prontidão explosiva para atacar. Deste modo, o lobo dominante aparece maior e tem vantagem para agarrar o focinho e a nuca do que se encontra mais submisso que, por sua vez, tende a murchar e ir de encontro ao solo. Esse comportamento não prepara o corpo do lobo para o combate, mas expressa amistosidade e a intenção de não confrontar o companheiro, em uma postura conhecida como submissão ativa. De fato, a posição e o movimento do rabo são responsáveis por expressar estados emocionais em formas variadas de interação. Mech (2007) salienta que o rabo levantado e acompanhado de movimentação súbita e rápida está associado a uma disposição agressiva. Por outro lado, um abanar relaxado com grande amplitude significa uma disposição amigável.

O terceiro princípio é denominado de ações devidas à constituição do sistema nervoso e se caracteriza por movimentos expressivos independentes do hábito ou controle intencional. Sempre que ocorre um estímulo no aparato sensório, uma força nervosa é gerada e transmitida pelo corpo pelas conexões de células nervosas. De fato, todo movimento expressivo de um animal está baseado no modo como é constituído o seu sistema nervoso. O fator distintivo deste princípio é que são consideradas apenas as expressões que independem da vontade ou intencionalidade, e que não são explicados pelos hábitos associados úteis ou pela antítese.

Por ser uma característica presente em inúmeras espécies, o tremor muscular é um caso exemplar de movimento expressivo associado à constituição do sistema nervoso. Esse movimento expressivo é ocasionado tanto pelo frio, febre, medo, fadiga ou tristeza, quanto pelo entusiasmo, contentamento e diversão. Dentre essas emoções, Darwin (2000) coloca que o medo, a raiva, a tristeza e o entusiasmo são os que mais causam tremores no corpo. O motivo é que, ainda que não possua utilidade prática e atrapalhe a coordenação motora, o tremor muscular está usualmente associado a uma intensa carga emocional. 
Como o tremor é algumas vezes provocado pela fúria, muito antes de o cansaço tomar conta, e como outras vezes acompanha uma grande alegria, parece que qualquer estimulação intensa do sistema nervoso é capaz de interromper o fluxo contínuo de força nervosa para os músculos (DARWIN, 2000, p. 72).

Os batimentos cardíacos associados a cargas emocionais também estão baseados no princípio em questão. $O$ coração é sensível à excitação dos nervos sensitivos, fazendo com que seja afetado sempre que o sistema nervoso é estimulado. Ainda que a frequência cardíaca possa ser influenciada por técnicas respiratórias, estas tendem a ser reativas com relação a uma situação já posta. Por exemplo, muitos movimentos vinculados à raiva são passíveis de controle voluntário, tais como o cerrar de punhos ou vocalizações intensas, mas o mesmo não se aplica às reações do coração. O mesmo ocorre com relação aos músculos faciais responsáveis por expressar emoções que se tenta ativamente esconder, como o tremer dos lábios quando se busca evitar o choro. Mesmo reprimindo os movimentos expressivos inerentes a tristeza, o corpo encontra formas alternativas de manifestá-la a partir da constituição psicobiológica do sistema nervoso.

Identificar os princípios que subjazem movimentos expressivos auxilia na compreensão da natureza das emoções, dando a plausibilidade de ambos possuírem o mesmo fundamento. Tanto o lobo selvagem quanto a sua versão domesticada, o cachorro, possuem comportamentos semelhantes para expressar intenções hostis ou amistosas. Caso a mesma uniformidade seja encontrada entre humanos, então isto consistirá em uma forte evidência de que tanto as expressões como as emoções comunicadas por elas possuem a mesma natureza. Isso reforçará a perspectiva evolucionista, a qual coloca que tanto os movimentos expressivos quanto as emoções que estão sendo comunicadas possuem uma base psicobiológica. 


\section{0 fundamento psicobiológico das emoções de orgulho e vergonha}

Animais sociais têm no êxito de seus atos um fator que influenciará na sua posição hierárquica dentro do grupo. Em relações desta natureza, tanto o orgulho é uma resposta emocional identificado com o sucesso como a vergonha o é com relação ao fracasso ${ }^{19}$. Conforme visto anteriormente, Ekman (1999) incluiu ambas as emoções no conjunto de emoções básicas, o que não impediu que abordagens construtivistas e perspectivas evolucionistas discutissem sobre qual a fundamentação das mesmas. Nesta sessão, será analisado um estudo de caso que reforça a hipótese de que orgulho e vergonha possuem uma base psicobiológica. ${ }^{20}$

Tracy e Matsumoto (2008) examinaram a origem de expressões não verbais de orgulho e vergonha. Foram realizadas análises dos movimentos expressivos realizados em situações de vitória e derrota nos Jogos Olímpicos e Paralímpicos de Atenas tanto de atletas com visão normal quanto de cegos congênitos e não congênitos. Os resultados mostram que os atletas deficientes visuais apresentaram os mesmos movimentos expressivos associados ao orgulho e a vergonha como resposta à vitória ou à derrota.

Os mesmos movimentos expressos pelos atletas vitoriosos, como a postura altiva e a cabeça inclinada, foram encontrados por de Wall (2007) em chimpanzés (Pan troglogytes) após derrotarem um rival. Tracy e Robins (2008) relatam que a expressão não verbal de orgulho é identificada com precisão em crianças a partir dos quatro anos de idade em diferentes culturas, incluindo sociedades semialfabetizadas ou altamente isoladas. De fato, a análise de Tracy e Matsumoto (2008) ressalta o papel

\footnotetext{
19 Segundo Darwin (2000), o orgulho e a vergonha são emoções identificadas por expressões não-verbais discretas, porém universalmente reconhecidas por membros da mesma espécie. Especificamente, elas estão associadas com expressões relacionadas a comportamentos de dominação e submissão.

20 O leitor poderá se aprofundar nessa questão a partir dos trabalhos de Maslow (1963), Schaller (1963), de Wall (2007) e Tracy e Robins (2008). Em linhas gerais, os autores relatam que o ato intimidador de bater as mãos no peito encontrado em gorilas das montanhas (Gorilla beringei) e posturas associadas a autoconfiança observadas em seres humanos possuem a mesma origem.
} 
do aculturamento como moderador da intensidade expressiva em atletas com visão normal, com a divisão ocorrendo entre culturas individualistas e coletivistas. Todavia, o mesmo fator não foi encontrado em atletas com deficiência visual, o que mantém forte o argumento de que emoções básicas socialmente funcionais possuem uma base psicobiológica.

Considerando a funcionalidade dos movimentos expressivos, o orgulho caracterizado por uma postura altiva e a cabeça inclinada para cima, acompanhadas do ato de inflar e bater no peito, comunica superioridade pela elevação da altura aos demais membros do grupo. Esse movimento é homólogo ao encontrado em lobos, que expressam superioridade ao erguer o rabo e as orelhas e trotar de modo ao seu focinho ficar acima da cabeça do restante da alcateia. O valor adaptativo da expressão do orgulho está associado ao seu fator de risco. Em um primeiro momento, tornar-se maior pode revelar a presença a um predador e aumentar as chances de sofrer um ataque. No entanto, entre animais sociais, esse movimento expressivo pode inibir tentativas de desafio pelos próprios companheiros, acarretando uma maior harmonia social e consequente economia de energia para enfrentar ameaças externas.

A vergonha tem como expressão principal a inclinação da cabeça para baixo e o encolhimento dos ombros, sendo compatível com o princípio da antítese. No caso de lobos, esse mesmo princípio é identificado no colocar do rabo entre as pernas e recolhimento das orelhas, associados a um caminhar mais rente ao solo. A expressão de vergonha característica de primatas e canídeos possui uma estrutura homóloga e comunica uma submissão aos companheiros de grupo. O ponto a ser considerado é a hipótese de que essas emoções estão presentes em determinadas espécies por sua funcionalidade adaptativa, ou seja, servir como reguladoras sociais que indicam a transgressão ou cumprimento de uma norma.

Em humanos, a ancestral exibição de submissão pode ter sido ritualizada numa expressão de vergonha que também servia a uma função secundária: apaziguar os espectadores que observam a falha. Ao comunicar não verbalmente a percepção 
da transgressão, o indivíduo pode manter sua reputação como um membro confiável do grupo que aceita as normas sociais (TRACY; MATSUMOTO, 2008, p. 11655, tradução nossa) ${ }^{21}$.

Keltner et al. (1997) colocam que comportamentos de apaziguamento levam à reconciliação social pela sinalização de aceitação das normas sociais, evocando emoções que estimulam ações pró-sociais e reduzem a agressão. Duas linhas de evidência atestam essa hipótese no que toca ao papel da vergonha. Miller e Tangney (1994) ressaltam que o enrubescimento é um sinal externo que identifica a propensão a seguir normas sociais. Keltner (1995) relata que a inclinação a comportamentos antissociais está vinculada à menor expressão de vergonha relativa à censura de grupos externos. Em suma, a vergonha consiste em um marcador externo que comunica uma tendência maior de aderir às normas sociais.

Comportamentos de submissão ativa são expressos pelo ato de se colocar em uma posição inferior aos demais. Isso comunica a aceitação da derrota, seja ela advinda de um confronto direto ou da descoberta de uma transgressão social, como roubar comida dos filhotes. Outra funcionalidade desse comportamento é a de comunicar a derrota e evitar a necessidade de um conflito, poupando recursos energéticos. A perspectiva evolucionista defendida neste artigo não é reducionista. Portanto, cabe verificar o papel que construções culturais, entendidas aqui como fatores externos, podem desempenhar na expressão dessas emoções específicas.

\subsection{O fundamento evolutivo das emoções de orgulho e vergonha}

Uma análise realizada por Tracy e Matsumoto (2008) identificou movimentos expressivos espontâneos e não verbais, realizados no mesmo

\footnotetext{
21 Do original: In humans, the ancient submission display may have been ritualized into a shame expression that also serves a secondary function: appeasing onlookers who observed the failure. By nonverbally communicating an awareness of one's transgression, the individual can maintain his/her reputation as a trusted group member who accepts social norms.
} 
contexto, de atletas com visão normal, cegos congênitos e não congênitos. Os medalhistas olímpicos foram divididos também dentro de grupos com origem cultural coletivista e individualista, valores seculares e religiosos, sobrevivência e autoexpressão e a importância dada à segurança, saúde e infraestrutura de seu país de origem. Desta forma, caso as expressões de orgulho e vergonha entre os atletas sejam tão amplas quanto as suas culturas, então a abordagem culturalista terá um forte argumento em seu favor. Entretanto, os autores relatam que todos os atletas apresentaram as mesmas expressões espontâneas de orgulho e vergonha, com a cultura sendo uma variável com relação à intensidade.

[...] vários componentes da expressão de vergonha (ombros caídos e peito contraído) são exibidos em resposta a falha por indivíduos com visão normal, cegos e cegos congênitos. Estes achados não podem ser atribuídos à variação compartilhada com qualquer outra expressão negativa; de fato, os comportamentos relevantes à vergonha foram um preditor melhor de quando um indivíduo perde, do que comportamentos associados a qualquer outra emoção negativa, exceto o medo (TRACY; MATSUMOTO, 2008, p. 11658, tradução nossa) ${ }^{22}$.

Atletas com visão normal vindos de culturas individualistas expressaram vergonha com menor intensidade do que aqueles criados em contextos culturais coletivistas. Isso ficou demarcado pela reticência apresentada no ato de inclinar a cabeça para baixo e esconder o rosto, traços característicos dessa emoção. Tracy e Matsumoto (2008) explicam esse comportamento pelo estigma social que demonstrações de vergonha têm no país de origem destes atletas. O ponto é que, da inibição de uma

22 Do original: [...] several components of the shame expression (slumped shoulders and narrowed chest) are displayed in response to failure by sighted, blind, and congenitally blind individuals. These findings could not be attributed to shared variance with any other negative emotion expression; in fact, shame-relevant behaviors were a better predictor of whether an individual lost than were behaviors associated with any other negative emotion except fear. 
emoção não decorre que ela não foi sentida. Essa hipótese é reforçada pelo fato que nenhum atleta com cegueira congênita reprimiu a vergonha, visto que eles não possuem os mesmos sinalizadores externos para inibir determinadas emoções. Afinal, a cegueira congênita confere menor ciência a signos culturais transmitidos pela imitação visual, tornando-os mais imunes a esse tipo de influência nos seus movimentos expressivos.

[...] o fato de que esses indivíduos apresentaram as maiores evidências de uma resposta comportamental de vergonha, sugere que esse comportamento é uma resposta inata, resultado do processo evolutivo, e a ausência de uma expressão clara de vergonha entre atletas com visão normal de certas culturas representa uma regulação de certas emoções específica daquela cultura (TRACY E MATSUMOTO, 2008, p. 11658, tradução nossa ${ }^{23}$.

Com relação aos movimentos expressivos associados ao orgulho, Tracy e Matsumoto (2008) também reforçam que eles são uma discreta configuração de comportamento produzido em situações naturalmente válidas, que evoluiu como uma resposta comportamental para ações bem-sucedidas. Neste caso, os movimentos expressivos apresentados por todos os atletas foram idênticos entre si. A única exceção foi o ato de colocar as mãos no quadril, que é considerado uma manifestação da emoção de orgulho e que não foi apresentada por todos os atletas.

A constatação de que indivíduos com cegueira congênita, que não poderiam ter aprendido a mostrar expressões de orgulho pela observação de outras pessoas, não obstante, apresentaram esses mesmos comportamentos, nas mes-

\footnotetext{
23 Do original: [...] the fact that these individuals showed the greatest evidence of a shame behavioral response suggests that these behaviors are the evolved, innate response, and the absence of a clear shame expression among sighted athletes from certain cultures represents culture-specific emotion regulation.
} 
mas situações, sugere que é pouco provável que a resposta comportamental para o sucesso seja algo aprendido (TRACY; MATSUMOTO, 2008, p. 11658, tradução nossa) $)^{24}$.

A cegueira congênita impossibilita qualquer aprendizado de movimentos expressivos por imitação. Considerando a notável correlação encontrada por Tracy e Matsumoto no modo como o orgulho e a vergonha são expressos, é implausível que ambas resultem de aculturamento. É verdade que crianças cegas podem ser educadas para realizar algumas expressões emocionais, mas é absurdo considerar que todos os pais ao redor do mundo ensinaram de forma idêntica até mesmo os movimentos mais sutis.

Ao responder ao sucesso com comportamentos que expandem o corpo e são identificados de forma confiável como orgulho, indivíduos anunciam seu feito e, desse modo, podem assegurar a continuidade de sua posição e aceitação dentro do seu grupo social (TRACY; MATSUMOTO, 2008, p. 11658, tradução nossa) $)^{25}$.

Os resultados apresentados por Tracy e Matsumoto (2008) sugerem que as expressões de orgulho e vergonha, assim como as emoções em si, caracterizam um comportamento expressivo não verbal e instintivo. A universalidade ocorre devido a um sistema psicobiológico característico das espécies capazes de senti-las. Os gatilhos irão variar não só de espécie para espécie, mas também pelo ambiente e contexto no qual estes animais estão inseridos, que pode ser desde a escassez de alimento, até uma cultura conservadora. Em outras palavras, as emoções e os movimentos

\footnotetext{
24 Do original: The finding that congenitally blind individuals Who could not have learned to show the pride expression from watching others nonetheless displayed these same behaviors in the same situation suggests that this behavioral response to success is unlikely to be learned.

25 Do original: By responding to success with behaviors that expand the body and are reliably identified as pride, individuals advertise their accomplishment, and thereby may ensure their continued status and acceptance within their social group.
} 
que as expressam evoluíram devido à sua funcionalidade adaptativa, sendo preservada no processo de seleção natural por estimular comportamentos pró-sociais em animais que dependem do grupo para sobreviver. Orgulho e vergonha estão em oposição direta e podem ser explicados, respectivamente, pelo princípio dos hábitos associados úteis e pelo princípio da antítese. Em suma, estes resultados suportam a ideia de que emoções evoluíram como sistemas adaptativos cuja função também é regular o convívio social.

\section{Considerações finais}

É fundamental a qualquer teoria emotivista sobre comportamentos normativos compreender a natureza das emoções. Considerando que um efeito possui a mesma origem que sua causa, o suporte empírico à hipótese de que movimentos expressivos são instintivos reforça a perspectiva evolucionista sobre o tema. Afinal, a comprovação empírica de que esses movimentos não resultam de aculturamentos atesta que as emoções expressas têm a mesma natureza. Da mesma forma, foram apresentados comportamentos sociais motivados por emoções básicas e expressos de forma homóloga em diferentes espécies, delineando o seu valor adaptativo para além da esfera humana. Por sua vez, a cultura ou outros fatores ambientais influenciarão as emoções apenas na medida em que existe um sistema psicobiológico apto a recebê-las. Concluindo, a emoção e os movimentos expressivos associados a elas resultam de sistemas psicobiológicos inerentes a determinadas espécies; enquanto influências externas poderão definir os gatilhos que despertam essas emoções, assim como a intensidade com a qual serão sentidas.

\section{Referências}

AVERILL, J. R. A constructivist view of emotion. In: PLUTCHIK, R.; KELLERMAN, $\mathrm{H}$. (ed.). Emotion: theory, research and experience. New York: Academic, 1980. (Theories of Emotion, v. 1). p. 305-339. https://doi.org/10.1016/b9780-12-558701-3.50018-1 
BELL, C. Essays on the anatomy and philosophy of expression. 2nd ed. London: Murray, 1824.

BENSHOOF, L.; THORNHILL, R. The evolution of monogamy and concealed ovulation in humans. Journal of Social Biological Structures, [s. I.], v. 2, n. 2, p. 95-106, 1979. https://doi.org/10.1016/0140-1750(79)90001-0

BRIGGS, J. L. Never in anger: portrait of an Eskimo family. Cambridge: Harvard University, 1970.

DAMASIO, A. R. The feeling of what happens: body and emotion in the making of consciousness. New York: Harcourt Brace \& Company, 1999. https://doi. org/10.26439/persona2000.no03.1708

DARWIN, C. A expressão das emoções no homem e nos animais. São Paulo: Companhia das Letras, 2000.

DAVIDOFF, J. B.; DAVIES, I.; ROBERSON, D. Colour categories in a stone-age tribe. Nature, London, v. 398, p. 203-204, 1999. https://doi.org/10.1038/18335

DE WAAL, F. Chimpanzee politics: power and sex among apes. Baltimore: John Hopkins University, 2007.

DOI, T. The anatomy of dependence. New York: Kodansha International, 1973. DUCHENNE, G. B. Mécanisme de la physionomie humaine, où analyse électro-physiologique de ses différents modes de l'expression. Paris: Jules Renouard, 1862. https://doi.org/10.5962/bhl.title.50402

EKMAN, P. Basic emotions. In: DALGLEISH, D.; POWER, T. (ed.). The handbook of cognition and emotion. New York: John Wiley \& Sons, 1999. p. 45-60.

EKMAN, P.; SORENSON, E. R.; FRIESEN. W. V. Pan-cultural elements in facial displays of emotions. Science, New York, v. 164, n. 3875, p. 86-88, 1969. https://doi.org/10.1002/0470013494.ch3

FRANK, R. Passions within reason: the strategic role of the emotions. New York: Norton, 1988.

GREENSPAN, P. Emotional strategies and rationality. Ethics, Chicago, v. 110, n. 3, p. 469-87, 2000.

GRIFFITHS, P. What emotions really are? Chicago: University of Chicago, 1997. JAMES, W. What is an emotion? In: DUNLAP, K. (ed.). The emotions. Baltimore: Waverly, 1922. p. 11-30. 
KELTNER, D. The signs of appeasement: evidence for the distinct displays of embarrassment, amusement, and shame. Journal of Personality and Social Psychology, Washington, v. 68, n. 3, p. 441-454, 1995. https://doi. org/10.1037//0022-3514.68.3.441

KELTNER, D.; BUSWELL, B. N.; YOUNG, R. Appeasement in human emotion, personality, and social practice. Aggressive Behavior, New York, v. 23, n. 5, p. 359-374, 1997. https://doi.org/10.1002/(sici)1098-2337(1997)23:5\%3C359::aid-ab5\%3E3.0.co;2-d

LANGE, C. G. The emotions. In: DUNLAP, K. (ed.). The emotions. Baltimore: Waverly, 1922. p. 33-90.

MACLEAN, P. D. Cerebral evolution of emotion. In: LEWIS, M.; HAVILAND, J. M. (ed.). Handbook of emotions. New York: Guilford, 1993. p. 67-83.

MARKUS, H. R.; KITAYAMA, S. Culture and the self: implications for cognition, emotion and motivation. Psychological Review, Washington, v. 98, n. 2, p. 224-253, 1991. https://doi.org/10.1037//0033-295x.98.2.224

MASLOW, A. H. The role of dominance in the social and sexual behavior of infra-human primates: I. Observation at Vilas Park Zoo. Journal of Gerontology, Washington, v. 48, p. 261-277, 1936. https://doi.org/10.1080/08856559.193 6.10533730

$\mathrm{MECH}, \mathrm{L}$. D. Alpha status, dominance, and division of labor in wolf packs. Canadian Journal of Zoology, Ottawa, v. 77, n. 8, p. 1196-1203, 1999.

$\mathrm{MECH}, \mathrm{L}$. D. The wolf: the ecology and behavior of an endangered species. 13th Minneapolis: University of Minnesota, 2007. https://doi.org/10.1139/ cjz-77-8-1196

MILLER R. S.; TANGNEY, J. P. Differentiating embarrassment from shame. Journal of Social and Clinical Psychology, [s. l.], v. 13, n. 3, p. 273-287, 1994. https://doi.org/10.1521/jscp.1994.13.3.273

OATLEY, K.; JOHNSON-LAIRD, P. Towards a cognitive theory of emotions. Cognition \& Emotion, Hove, v. 1, n. 1, p. 29-50, 1987.

PINKER, S. How the mind works. New York: Norton, 1997.

PLUTCHIK, R. Emotion: a psychoevolutionary synthesis. New York: Harper \& Row, 1980.

PRINZ, J. J. Gut reactions: a perceptual theory of emotion. New York: Oxford University, 2004. 
ROBERSON, D.; DAVIDOFF, J. Color categories: evidence for the cultural relativity hypothesis. Cognitive Psychology, New York, v. 50, n. 4, p. 378-411, 2005. https://doi.org/10.1016/j.cogpsych.2004.10.001

SCHALLER, G. B. The Mountain Gorilla: ecology and behavior. Chicago: University of Chicago, 1963.

SCHENKEL, R. Expression-studies of wolves. Behavior, [s. l.], v. 1, p. 81-129, 1947. SPENCER, H. The principles of psychology. London: Longman, 1855.

SOLOMON, R. Emotions and choice. In: RORTY, A. (ed.). Explaining emotions. Berkeley: University of California, 1980. p. 251-271.

TRACY, J. L.; MATSUMOTO, D. The spontaneous display of pride and shame: evidence for biologically innate nonverbal displays. Proceedings of the National Academy of Sciences, Washington, v. 105, n. 33, p. 11655-11660, 2008. https:// doi.org/10.1073/pnas.0802686105

TRACY, J. L.; ROBINS, R. W. The nonverbal expression of pride: Evidence for cross-culturally recognition. Journal of Personality and Social Psychology, Washington, v. 94, n. 3, p. 516-530, 2008. https://doi.org/10.1037/00223514.94.3.516

TRIVERS, R. L. The evolution of reciprocal altruism. Quarterly Review of Biology, New York, v. 46, n. 1, p. 35-57, 1971. https://doi.org/10.1086/406755

\section{Endereço postal}

\section{Matheus de Mesquita Silveira}

Universidade de Caxias do Sul

Rua Francisco Getúlio Vargas, 1130

CEP 95070-560 - Sala 302, Bloco E

Campus-Sede - Caxias do Sul - RS 